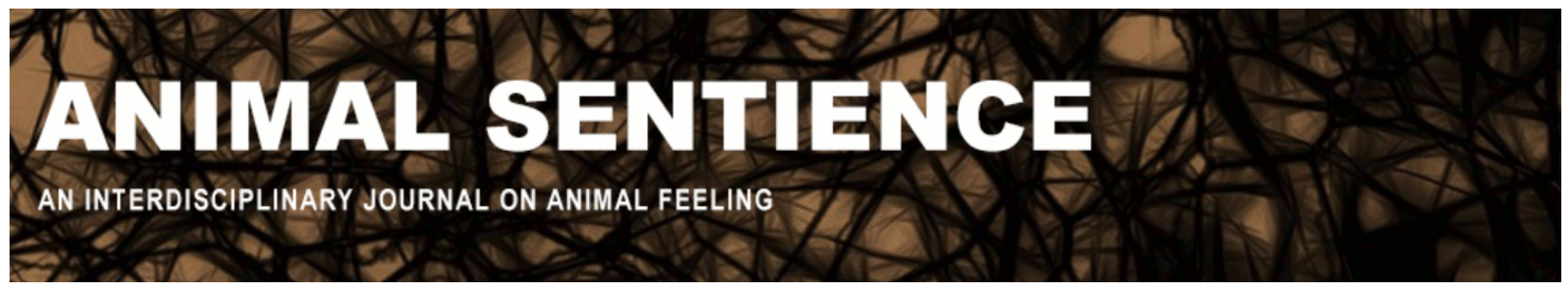

Ristau, Carolyn A. (2016) Beginnings: Physics, sentience and LUCA. Animal Sentience 11(4)

DOI: $10.51291 / 2377-7478.1161$

Date of submission: 2016-09-05

Date of acceptance: 2016-09-09

(c) (†)

This article has appeared in the journal Animal

Sentience, a peer-reviewed journal on animal

cognition and feeling. It has been made open access,

free for all, by WellBeing International and deposited

in the WBI Studies Repository. For more information,

please contact

wbisr-info@wellbeingintl.org.

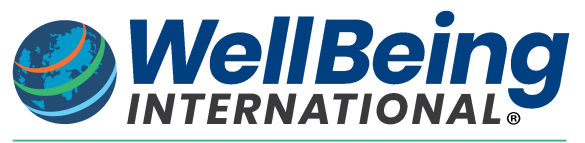

SOLUTIONS FOR PEOPLE, ANIMALS AND ENVIRONMENT 


\title{
Beginnings: Physics, sentience and LUCA
}

Commentary on Reber on Origins of Mind

\author{
Carolyn A. Ristau \\ Little Neck, New York
}

\begin{abstract}
According to Reber's model, Cellular Basis of Consciousness (CBC), sentience had its origins in a unicellular organism and is an inherent property of living, mobile organic forms. He argues by analogy to basic physical forces which he considers to be inherent properties of matter; I suggest that they are instead the stuff of scientific investigation in physics. I find no convincing argument that sentience had to begin in endogenously mobile cells, a criterial attribute of the originator cell(s)for sentience according to CBC. Non-endogenously mobile cells, (i.e., plants or precursors) in a moving environment would suffice. Despite my concerns and the need for at least a small "miracle" in his and others' models to instantiate sentience, I applaud a bottom-up approach such as Reber's for our scientific investigation of consciousness.
\end{abstract}

Keywords: consciousness, animal sentience, Griffin, hard problem, physics, evolution, LUCA

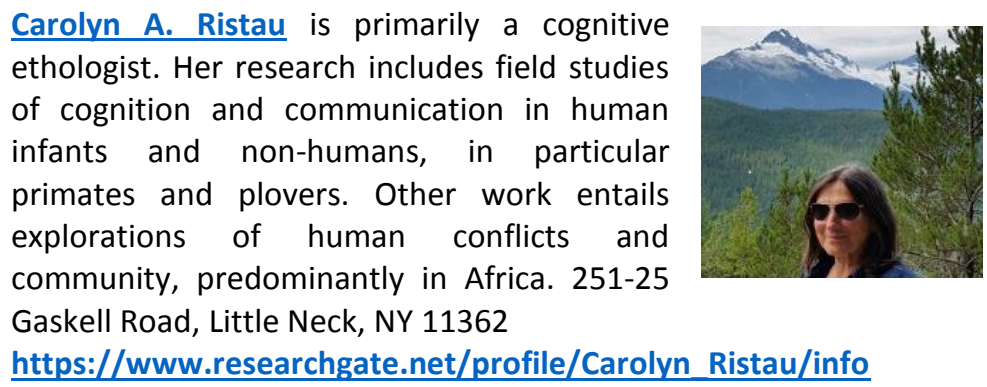

I do not know how consciousness arose/arises and neither does anyone else I've encountered or tried to understand. Nevertheless, Reber's (2016) Cellular Basis of Consciousness (CBC) model is a bottom-up, evolutionary approach that could lead to useful studies of the phenomenon of sentience in non-humans.

The resistance to attempts to study conscious phenomena in animals has been strong, though it is easing. Donald R. Griffin's (1976) small seminal book, The Question of Animal Awareness, inspired both appreciation (that a well-known, respected scientist had raised the issue again) and condemnations. One extreme opposing view called another of his books (Griffin, 1984) "The Satanic Verses of Animal Behavior" (noted in Griffin, 2001; Ristau, 2005).

Notwithstanding the importance of scientific investigation of non-human sentience and the potential usefulness of Reber's approach, I do disagree with several of his tenets.

1. The Analogy to Physics. Reber states "Particular kinds of biological stuff carry with them particular properties" (p. 7). These properties are stated to be inherent, by analogy to gravity as 
a property of mass: for example, "When you get nuclear particles you get the weak and strong nuclear forces; when you get mass you get the warp in space-time we call gravity; when you get electrons you get the electromagnetic force ... and if there turn out to be more fundamental properties, if there is a deeper level, the argument would hold there instead" (p. 6).

But gravity is not a property of mass. "The Higgs field gives particles mass, not gravity." "Charges on quarks can be $+1 / 3,-1 / 3,+2 / 3$ or $-2 / 3$ [Electron Volts], i.e. less than the electron's charge" (Hagopian, 2016, personal communication). The various forces are the stuff of physics that is to be investigated; they are not simply inherent properties. Recently, it was thought that a blip in a graph of high speed collisions at CERN might be the sought-after "graviton" that would help explain gravity, but it turned out to be just a blip, a statistical fluke (Overbye, 2016). Simply stating that sentience is a property of certain kinds of cells is likewise not an answer.

2. Hardware Dependence. I (and others) do not agree that the actual stuff of consciousness needs to be biologically based, by which Reber seems to mean "living organic forms." I do not mean that a programmed machine is likely to become conscious at some undetermined level of programming complexity, but I know no reason sentience needs to be carbon based. Perhaps it is so on this planet, but if important analogies are made to the physics of the universe, one must entertain the realms of the physically possible.

3. Characteristics of a Cell. Reber writes about the cellular origin of consciousness: "Any organism with flexible cell walls, a sensitivity to its surrounds and the capacity for locomotion will possess the biological foundations of mind and consciousness (p. 4)." Sensitivity to surroundings does seem essential, but "flexibility" of the cell wall is problematic, for, at the least, cells grow, which requires some flexibility. Reber cites the work of Dener, Kacelnik \& Shemesh (2016) showing that plants make risk-sensitive root-growth decisions, but he then excludes plants as potentially sentient beings because they lack endogenous locomotion. Locomotion is helpful to secure food, to escape, to reproduce. However, if, as is widely accepted, the origin of life forms indeed occurred in a primordial soup, then the need for locomotion is diminished. A fluid environment is likely to be moving. The liquid carries food. Cells and creatures would probably be dwelling in colonies, rather than in isolation. Thus an individual cell is safer in a colony because the other cell might be the one destroyed by a storm or eaten by a predator. A cell might be able to condense into a hard, inedible core for protection. Once they evolve, sperm or eggs can be transported to a nearby recipient. An alternative theory suggests that life (LUCA, the Last Universal Common Ancestor) might have originated in hydrothermal vents in the deep sea; it also makes a more convincing case for the evolution of the existent types of energy use and provides an even more dynamic environment (Weiss et al., 2016).

However, once locomotion is no longer deemed a necessary characteristic of originator sentient entities, the possibility exists that non-animal entities - for example, plants and other early life forms - could be sentient. The originator, non-mobile entities would presumably find discriminatory abilities and sentience useful just as a mobile entity would. I am not proclaiming the existence of thinking and feeling plants. I simply note that we still do not have defining 
criteria for the emergence or presence of sentience, so there is as yet no convincing reason why non-animal entities couldn't be sentient.

Plausibly, though, autonomously locomoting entities would face more pressures to have sentience, to "see/smell/feel/" their external environment, to evolve improved means to manage their locomotion, to be motivated for actions not only via stimulus-response mechanisms, but through some experienced state of being or emotion. No doubt nonautonomously moving entities would also benefit from these capacities, but the case could be made that the likely complexities encountered by highly mobile autonomously moving entities could create additional pressures to promote sentience.

Other researchers, for example, Feinberg \& Mallatt (2016; Mallatt \& Fenberg 2016), have suggested other criteria for the origin of sentience in an organism, deconstructing Chalmers's (1995) "hard problem" into several concerns. However, in their scenario and Reber's, we still need at least a "small miracle" to attain even an iota of sentient capacity. Chalmers's "hard problem" has not been solved and it has not gone away.

Nevertheless, unless we accept divine installation of some sentient capacity (e.g., Descartes, 1649), an evolutionary framework is the only viable one. A top-down approach can sometimes be useful, perhaps adopting an intentional stance as I did in investigating the likely mentations of plovers protecting their eggs and young when performing broken-wing displays (aka "injury feigning"). Adopting that pragmatic approach helped me design experiments and gain new understanding of the plovers (Ristau, 1991).

A bottom-up approach, however, has its own particular benefits, scientifically, intellectually and even morally (Harnad, 2016). Consciousness had to start somewhere. Evolution is practical and functional, most frequently building on what already exists.

In this regard, I think that Woodruff's (2016) comment that the bio-sensitivity underlying the locomotory mechanisms of bacteria with motor-driven flagella does not share genomic similarity with the neural mechanisms of sensing may be missing the essential point of Reber's CBC model. One does not, I think, have to find genetic continuity in a particular sensing ability. If sentience is an inherent property of such biological material, it can promote the evolution of greater levels and kinds of sentience in that and other sensing abilities. Nor does Occam's Razor destroy Reber's arguments. Occam's Razor is a suggested mode of conducting scientific inquiry and subsequent decision making regarding hypotheses. The simplest explanation is not "truth," nor is it always the most adequate one. Organisms have multiple backup systems for their survival; even the most fundamental atomic physics is ever-more complex; "simple" explanations fall by the wayside.

The plausibility of looking for consciousness at very low levels reminds one of Griffin's (1976) proposal, then outrageous, that consciousness could be particularly helpful for a "smallbrained" creature such as an insect, in place of needing to have myriads of neural programs to account for all the situations they encounter and their adaptive responses. 
Whether the first beginnings of sentience were in any living entity or just in cells with the attributes proposed by Reber, or it began only in animals, or at the much higher levels suggested by Feinberg \& Mallatt (2016), I do not know - nor, I think, does anyone today. However, more and more people - both scientists and non-scientists - appear to be recognizing that species others than our own are sentient and that the deeper we explore the issue, the further "down" we seem to be finding at least suggestions of that sentience. Sentience still remains a "miracle," though: as Reber suggests, in his model, a rather small one.

\section{References}

Chalmers, D. J. (1995). Explaining consciousness: The hard problem. Journal of Consciousness Studies, 2, 200-19.

Dener, E., Kacelnik, A. \& Shemesh, H. (2016). Pea plants show risk sensitivity. Current Biology, 26, 1763-1767.

Descartes, R. (1649). Passions of the Soul. (originally published in French) (Trans. S. H. Voss. Indianapolis: Hackett Press; 1989).

Feinberg, T. E. \& Mallatt, J. (2016). The nature of primary consciousness: A new synthesis. Consciousness and Cognition, 43, 113-127. doi:10.1016/j.concog.2016.05.009

Griffin, D. R. (1976). The Question of Animal Awareness. New York: Rockefeller University Press. Griffin, D. R. (1984). Animal Thinking. Cambridge: Harvard University Press.

Griffin, D. R. (2001). Animal Mind ( $2^{\text {nd }}$ ed.). Chicago: University of Chicago Press.

Hagopian, S. (2016). Personal communication. Member of CMS team at CERN, which, along with the Atlas team, discovered the Higgs boson particle.

Harnad, S. (2016). Animal sentience: The other-minds problem. Animal Sentience 2016.097.

Mallatt, J. \& Feinberg, T. E. (2016) Insect consciousness: Fine-tuning the hypothesis. Animal Sentience 2016.118.

Overbye, D. (2016). The particle that wasn't. New York Times. August 5, revised August 10.

Reber, A. S. (2016). Caterpillars, consciousness and the origins of mind. Animal Sentience 2016.106.

Ristau, C. A. (1991). Aspects of the cognitive ethology of an injury-feigning bird, the Piping plover. In: C. A. Ristau (Ed.), Cognitive Ethology: The Minds of Other Animals. (Essays in Honor of Donald R. Griffin, pp. 91-126). Hillsdale, NJ: Lawrence Erlbaum Associates.

Ristau, C. A. (2005). Donald Redfield Griffin - A biographical memoir. Proceedings of the American Philosophical Society, 149(3), September, 399-411.

Weiss, M. C., Sousa, F.L., Mrnjavac, N., Neukirchen, S., Roettger, M., Nelson-Sathi, S. \& Martin, W. F. (2016). The physiology and habitat of the last universal common ancestor. Nature Microbiology. doi:10.1038/NMICROBIOL.2016.116 http://www.nature.com/articles/nmicrobiol2016116

Woodruff, M. L. (2016). Bacteria and the cellular basis of consciousness. Animal Sentience 2016.126. 